\title{
Clinical Presentation of Ulcerative Colitis Among Bangladeshi Population - Twenty Years Experience From A Tertiary Care Hospital in Bangladesh
}

\author{
Mohammad Shoaib Chowdhury ${ }^{1}$, Md. Masudur Rahman Khan ${ }^{2}$, Md. Zahidur Rahman ${ }^{2}$, Madhusudan Saha ${ }^{3}$, \\ Guru Prashad Dhakal, Projesh Kumar Roy ${ }^{5}$, A.S.M.A. Raihan ${ }^{6}$ \\ ${ }^{1}$ Medical Officer, Department of Gastroenterology, Bangabandhu Sheikh Mujib Medical University, ${ }^{2}$ Assistant Professor, Department of Gastroenterol- \\ ogy, Bangabandhu Sheikh Mujib Medical University, ${ }^{3}$ Associate Professor, Department of Medicine, North East Medical College, Sylhet, \\ ${ }^{4}$ Gastroenterologist, JDWNR Hospital, Thimphu, Bhutan, ${ }^{5}$ Professor, Department of Gastroenterology, Bangabandhu Sheikh Mujib Medical Univer- \\ sity, ${ }^{6}$ Professor and Chairman, Department of Gastroenterology, Bangabandhu Sheikh Mujib Medical University, Dhaka.
}

\begin{abstract}
:
Background : The prevalence of Ulcerative colitis has been increasingly reported from Western countries as well as other Asian countries. Our personal experience shows that Ulcerative colitis is not uncommon in our country and is being diagnosed more commonly. So, there is need to study the disease pattern in our country. Objective: To find out the clinical presentation, among Bangladeshi population. Methods : A hospital (Department of Gastroenterology, Bangabandhu Sheikh Mujib Medical University) based study registering previously diagnosed and newly diagnosed cases of Ulcerative colitis, was carried out from January 1990 to June 2010. Data that were obtained are: age and sex of the patients, clinical presentations like bloody diarrhoea, per rectal bleeding, diarrhoea without per rectal bleeding, urgency, tenesmus, abdominal pain, fever, anorexia, weakness, weight loss. Data regarding physical findings and extra intestinal manifestations were also recorded. Results : Out of 164 patients $65.24 \%$ (107) were male and $34.76 \%(57)$ were female. The male- female ratio was $1.88: 1$. Mean age of male patients was $36.14( \pm 11.66)$ years and mean age for female patients was $33.15( \pm 11.12)$ years. Maximum number of male patients were in 21-40 years age group $(65.42 \%, 70)$. Maximum number of female patients were in 21-30 years age group $(42.10 \%, 24)$. Maximum number of both male and female patients were in 21-30 years age group $(35.97 \%, 59)$. Clinical features of 164 patients showed that $87.28 \%(143)$ had bloody diarrhoea, 20.12\% (33) had per-rectal bleeding, 4.26\% (7) had diarrhoea without per rectal bleeding, 1.21\% (2) had urgency,5.48\% (9) had tenesmus, 33.53\% (55) had abdominal pain, 17.66\% (29) had fever, 18.29\% (30) had anorexia, weakness and $17.68 \%$ (29) had weight loss at their initial presentation. Physical examination of 164 patients revealed that $81(49.39 \%)$ patients had normal findings, $7(4.27 \%)$ patients had oedema and $83(50.61 \%)$ patients had anaemia. Extra intestinal features were absent in $143(87.20 \%)$ patients out of 164 patients. The rest $21(12.80 \%)$ patients had joint involvement and $2(1.21 \%)$ patients had ocular involvement. There was no patient with skin involvement. Conclusion : The clinical presentation of Ulcerative colitis in our country is mostly similar compared to other Asian and Western countries except higher male-female ratio, presence of oedema and wide variability of extra intestinal involvement. These differences are probably due to social and cultural reasons, poor nutritional status, in $\neg$ complete workup or records and influence of various environmental factors. To validate these results further prospective studies are needed.
\end{abstract}

Key words : Ulcerative Colitis, Clinical Presentation.

[BSMMUJ 2013; 6 (1): 16-20]

\section{Introduction:}

Ulcerative colitis is a chronic inflammatory disorder of the gastrointestinal tract that affects the large bowel and is a major disorder under the broad group of inflammatory bowel disease ${ }^{1}$.It is probably the result of the complex

Address of correspondence: Dr. Mohammad Shoaib Chowdhury Medical Officer, Department of Gastroenterology, BSMMU, Dhaka. E mail : shoaib@accesstel.net interaction of genetic susceptibility and numerous environmental influences ${ }^{2}$.

Ulcerative colitis may present at all ages, though diagnosis before the age of 5 years or after 75 year is uncommon. The peak incidence of UC occurs in the $2^{\text {nd }}$ and $3^{\text {rd }}$ decades of life. Studies have reported a second smaller peak in the elderly between the ages of 60 to 70 years ${ }^{1}$. The incidence is much lower before the age of 15 years ${ }^{3}$. 
Most studies have not shown any gender difference in the occurrence of the disease and a male to female ratio of nearly $1: 1$ applies to all age groups ${ }^{1}$.

Patients with UC may present with variety of symptoms which are diarrhoea, rectal bleeding, passage of mucus, tenesmus, urgency, and abdominal pain. In more severe case, fever and weight loss may be prominent ${ }^{1}$. The symptom complex tends to differ according to the extent of disease ${ }^{4}$. Patients with proctitis often have local symptoms of tenesmus, urgency, mucus and bleeding whereas patients with extensive colitis may have more diarrhoea, weight loss, fever, clinically significant blood loss and abdominal pain ${ }^{1}$. Patients with proctitis usually complain of passing fresh blood either separately from the stool or streaked on the surface of a normal or hard stool. Diarrhoea is common but not always present in patients with UC. Up to $30 \%$ of patients with proctitis or proctosigmoiditis may complain of constipation and hard stools $\mathrm{s}^{5}$. The pathophysiology of the diarrhoea in UC involves several mechanisms but failure to absorb salt and water is perhaps the predominant factor ${ }^{6}$. Urgency and tenesmus which are common symptoms when the rectum is inflamed, are caused by poor compliance and loss of the reservoir capacity of the inflamed rectum? ${ }^{7}$. Although ulcerative colitis primarily involves the colon, it is associated with manifestations in other organ systems. For some patients especially those with sclerosing cholangitis or ankylosing spondylitis, the extraintestinal manifestations may be more troublesome than the bowel disease ${ }^{3}$. The most common extraintestinal manifestation of IBD is arthritis $^{8,9,10}$. The two common dermal complications of IBD are pyoderma gangrenosum and erythema nodosum ${ }^{3}$. The ocular complications of IBD are uveitis and episcleritis ${ }^{11}$.

Many studies have been published describing various aspects of the disease from Europe and United states over the past 50 years. Some studies have also been published from Asian countries like China, Malaysia, Saudi Arabia, and India. However there are no data regarding the clinical presentation of $\mathrm{UC}$ among Bangladeshi population.

The aim of this study is to find out the clinical presentation of $\mathrm{UC}$ among Bangladeshi population.

\section{Methods:}

This was a retrospective observational study which was conducted in department of Gastroenterology, Bangabandhu Sheikh Mujib Medical University during the period of January 1990 to June 2010. As ulcerative colitis is a less common disease, patients who were diagnosed as ulcerative colitis in departmental ulcerative colitis record book on the basis of typical case history with chronic diarrhoea and/or blood/pus in the stool for more than four weeks or repeated episodes and typical sigmoidoscopic appearance ${ }^{12}$ from 1990 to 2010 were considered as study population. Patients diagnosed to have proctitis/colitis secondary to infectious cause (bacterial, protozoal, or parasitic) ,crohn's colitis, antibiotic associated colitis, ischemic and radiation colitis were excluded ${ }^{13}$. Data were obtained by careful review of the medical record of the patients enrolled in departmental UC record book as UC who attended the OPD follow up clinic or were admitted to the university hospital till 2010 . The information that were obtained are: age and sex of the patients, clinical presentations like bloody diarrhoea, per rectal bleeding, diarrhoea without per rectal bleeding, urgency, tenesmus, abdominal pain, fever, anorexia, weakness, weight loss. Patients of UC may present with completely normal physical findings or may have different degree of anaemia, oedema and data regarding these findings were also obtained. The information regarding extra intestinal manifestation like arthropathy, eye involvement and skin involvement were also recorded.

All necessary measures were taken to protect anonymity of subjects and the protocol was approved by Departmental Academic Faculty. Data were analysed using appropriate statistical tool ( SPSS ) and expressed as mean \pm $\mathrm{SD}$ and ratios and percentages.

\section{Results:}

A total of 164 patients were included in this study. Among them 107 (65.24\%) patients were male and 57 (34.76) were female; male-female ratio was 1.88: 1 .

Mean age for male patients was $36.14( \pm 11.66)$ years and mean age for female patients was $33.15( \pm 11.12)$ years.

Age distribution of patients were found as follows: Among the patients highest number ( 59, $35.97 \%)$ of patients were in age group 21-30 years. ( Table I).

Table-I

No of patients according to age group.

\begin{tabular}{lc}
\hline Age group & Number of patients (\%) \\
\hline $11-20$ & $11(6.70 \%)$ \\
$21-30$ & $59(35.97 \%)$ \\
$31-40$ & $47(28.65 \%)$ \\
$41-50$ & $35(21.34 \%)$ \\
$51-60$ & $8(4.87 \%)$ \\
$61-70$ & $2(1.21 \%)$ \\
$71-80$ & $2(1.21 \%)$ \\
\hline
\end{tabular}


Age distribution of male patients were found as follows : $5(4.67 \%)$ patients belonged to age group $11-20$ years, 35 $(32.71 \%)$ patients belonged to age group $21-30$ years, 35 (32.71\%) patients belonged to age group 31-40 years, 23 $(21.49 \%)$ patients belonged to age group $41-50$ years, 5 $(4.67 \%)$ patients belonged to age group 51-60 years, 2 $(1.86 \%)$ patients belonged to age group $61-70$ years and 2 $(1.86 \%)$ patients belonged to age group $71-80$ years.

Age distribution of female patients were as follows: 6 $(10.52 \%)$ patients belonged to age group 11-20 years, 24 $(42.10 \%)$ patients belonged to age group 21-30 years, 12 $(21.05 \%)$ patients belonged to age group 31- 40 years, 12 $(21.05 \%)$ patients belonged to age group 41 - 50 years, 3 $(5.26 \%)$ patients belonged to age group $51-60$ years. Age group 61- 70 years and 71-80 years had no patients.

Clinical features of 164 patients were as follows: 143 (87.29\%) patients had bloody diarrhoea. 33 (20.12\%) patients had per-rectal bleeding. Among the 33 patients 19 $(57.57 \%)$ had only per-rectal bleeding and 14 ( $42.43 \%)$ patients had both per-rectal bleeding and bloody diarrhoea. $7(4.26 \%)$ patients had diarrhoea without per-rectal bleeding. $2(1.21 \%)$ patients had urgency. $9(5.48 \%)$ patients had tenesmus. $55(33.53 \%)$ patients had abdominal pain. $29(17.68 \%)$ patients had fever. $30(18.29 \%)$ patients had anorexia and weakness. $29(17.68 \%)$ patients had weight loss.

Physical examination of 164 patients revealed that 81 $(49.39 \%)$ patients had normal findings, $7(4.27 \%)$ patients had oedema and $83(50.61 \%)$ patients had anaemia. Among the 83 anaemic patients $58(69.88 \%)$ had mild anaemia , $20(24.10 \%)$ had moderate anaemia and 5 ( $6.02 \%$ ) had severe anaemia.

Out of 164 patients of UC extra intestinal features were absent in $143(87.20 \%)$ patients. The rest $21(12.80 \%)$ patient had extra intestinal features. All the 21 patients 21 $(12.80 \%)$ had joint involvement and $2(1.21 \%)$ patients had ocular involvement. There was no patient with skin involvement.

\section{Discussion:}

The clinical picture as observed in the present series showed that maximum number of patients were in 21-40 years age group. In Poland it was 35-39 years 14, in Romania it was 35-44 years12. Among Asian countries in Saudi Arabia it was 20-39 years13, in Japan it was 20-24 years for male patients and 25-29 years for female patients 15 , in Pakistan it was 21-30 years16, in India it is $31-40$ years. ${ }^{17}$

Mean age for male patients was $36.14( \pm 11.66)$ years and for female patients it was $33.15( \pm 11.12)$ years in our country. In Austria it was $43.37( \pm 17.55)$ years ${ }^{18}$, in Romania it was 46.47 years for male patients and 44.48 years for female patients ${ }^{12}$, in Poland it was 53.4 years for male patients and 51.2 years for female patients ${ }^{14}$. Among Asian countries mean age was $42.9 \pm 13.2$ years for male patients and $45.95 \pm 13.4$ years for female patients in China $^{19}, 39.5$ years for male patients and 33 years for female patients in Saudi Arabia ${ }^{13}, 33 \pm 10$ years in Malaysia $^{20}, 48 \pm 7.39$ years in Philippine ${ }^{21}, 37.7$ years in Thailand $^{22}$ and it was 31.06 years for male patients and 32.9 years for female patients in India ${ }^{17}$.

The male : female ratio in our series was $1.88: 1$ which indicates a male predominance. Studies from western and other Asian countries did not show this male predominance ( $1.07: 1$ in Austria ${ }^{18}, 1.1: 1$ in Romania ${ }^{12}$, 1.05: 1 in Poland ${ }^{14}, 1.1: 1$ in China ${ }^{19}, 0.8: 1$ in Malaysia $^{20}, 19: 21$ in Thailand ${ }^{22}, 1: 1$ in Pakistan ${ }^{16}$ and 1.04: 1 in India ${ }^{17}$ ) except for Saudi Arabia ${ }^{13}$ where the ratio was $1.4: 1$. Also there was no female patients in 61-80 years age group in our study. This gender difference is probably due to social and cultural reasons, in this part of the world where fewer female patients attend hospital for symptom like per rectal bleeding .

The common clinical presenting features were bloody diarrhoea $(87.29 \%)$ and per rectal bleeding $(33.12 \%)$. Features like abdominal pain $(33.53 \%)$, anorexia and weakness $(18.29 \%)$, fever $(17.68 \%)$ and weight loss $(17.68 \%)$ were also present but less common. Diarrhoea without per rectal bleeding (4.26\%), tenesmus $(5.48 \%)$ and urgency $(1.21 \%)$ were uncommon presentations. In Poland out of 334 patients of ulcerative colitis most common manifestation was diarrhoea and the presence of the blood in the stool (217 patients, 93.94\%), 194 patients $(83.98 \%)$ complained of abdominal pain, while loss of weight was observed in 142 patients $(61.47 \%)^{14}$. In Saudi Arabia the main presenting symptoms were rectal bleeding, diarrhoea and abdominal pain. Constipation was occasionally present in patients having proctitis $^{13}$. Study in Philippine general hospital from 1999-2004 showed that ulcerative colitis patients presented with abdominal pain $(50 \%)$ or lower intestinal bleeding $(50 \%)$, anorexia $(25 \%)$, weight loss $(25 \%)$, 
presented with abdominal pain $(50 \%)$ or lower intestinal bleeding $(50 \%)$, anorexia $(25 \%)$, weight loss $(25 \%)$, diarrhoea $(25 \%)^{21}$. In India out of 120 patients majority of the patients presented with intestinal symptoms like chronic diarrhoea $(\mathrm{n}=95)$ and/or rectal bleeding $(\mathrm{n}=80)^{17}$.

In our study physical examination of 164 patients revealed that $81(49.39 \%)$ patients had normal findings, $7(4.27 \%)$ patients had oedema and $83(50.61 \%)$ patients had anaemia. This is similar with the findings of Western country like Poland where out of 231 ulcerative colitis patients $142(61.47 \%)$ had anemia ${ }^{14}$. But presence of oedema in our study was not observed in other studies. This difference is probably due to lower nutritional status of our country which needs further evaluation.

In our study $21(12.80 \%)$ had extra intestinal features. All the $21(12.80 \%)$ patients had joint involvement and 2 $(1.21 \%)$ patients had ocular involvement. There was no patient with skin involvement. One study in China showed that out of 379 patients of ulcerative colitis $2.8 \%$ (9) patients had arthritis and $0.9 \%$ (3) patients had ocular (iritis or conjunctivitis) involvement ${ }^{19}$. In Saudi Arabia ulcerative colitis was diagnosed in 80 Saudi nationals, among them extra intestinal manifestations were not seen $^{13}$. In another study conducted in Malaysia extra intestinal manifestations occurred in only $5(11.9 \%)$ patients. $3(7.1 \%)$ patients had arthropathy including 1 $(2.4 \%)$ patient with sacroiliitis. Erythema nodosum occurred in $2(4.8 \%)$ and pyoderma gangrenosum in 1 $(2.4 \%)^{20}$ patient.

Ulcerative colitis in the Indian population of Durban revealed that extra-intestinal manifestations were $\operatorname{rare}^{23}$. A clinical study and long term follow-up of ulcerative colitis in Thailand showed that extraintestinal manifestations occurred in 20 per cent patients ${ }^{22}$. A study done on 112 patients with ulcerative colitis in Iran revealed the absence of skin manifestations ${ }^{24}$. A study from department of Gastroenterology, Postgraduate Institute of Medical Education and Research, Chandigarh, showed that one hundred and fifty patients of idiopathic ulcerative colitis had extraintestinal manifestations by clinical, radiological and biochemical means. One or more such manifestations occurred in $34.7 \%$ of patients. Sacroiliitis $(14 \%)$ and peripheral arthritis $(10.7 \%)$ were the commonest manifestations, followed by ocular ( $8 \%$ ), mucocutaneous $(2.7 \%)$, vascular $(2 \%)$ and hepatobiliary $(1.3 \%)$ manifestations. It was concluded that the incidence and spectrum of extraintestinal manifestations in Indian patients with idiopathic ulcerative colitis were similar to those in western patients ${ }^{25}$. In another study in India, out of 120 patients of ulcerative colitis systemic complications were as follows: arthralgias in 7 patients and 3 patients had arthritis. 2 patients had sclerosing cholangitis. No patient had pyoderma gangrenosum, erythema nodosum or eye involvement ${ }^{17}$.

\section{Conclusion:}

Because of diagnostic accuracy due to availability of flexible endoscope, improved technology and increased awareness, the clinical presentation of ulcerative colitis between our country and other Asian and Western countries is almost similar except for higher male female ratio, presence of oedema and wide variability of extra intestinal involvement. These difference are probably due to social and cultural reasons, poor nutritional status, in $\neg$ complete workup or records and influence of various environmental factors. To validate these results further prospective studies are needed. For this the initiation of disease registry throughout the country is recommended.

\section{Acknowledgement:}

We would like to acknowledge the great contribution of Prof. Mahmud Hasan, former chairman, department of Gastroenterology, BSMMU who first initiated the departmental ulcerative colitis record book.

\section{Reference:}

1. Su C, Lichtenstein GR: Ulcerative Colitis. In: Feldman M, Friedman LS, Brandt LJ, eds. Slazenger and Fortran's gastrointestinal and liver Disease. Volume $2,8^{\text {th }}$ edition. USA: Saunders; 2007. p. 2499-2548.

2. Judge TA, Lichtenstein GR: Inflammatory Bowel Disease. In: Friedman SL, McQuaid KR, Grendell JH, eds. Current diagnosis $\&$ treatment in gastroenterology. $2^{\text {nd }}$ edition. USA: McGraw-Hill Companies; 2003. p. 108-130.

3. Stenson,WF, Hanauer SB, Cohen RD: Inflammatory bowel disease. In: Yamada T, Alpers DH, Kalloo AN, Kaplowitz N, Owyang C, Powell DW, eds. Textbook of Gastroenterology. Fifth Edition. UK: Blackwell Publishing Ltd; 2009. p.1386-1472.

4. Both H, Torp-Pedersen K, Kreiner S, Hendriksen C, Binder V. Clinical appearance at diagnosis of ulcerative colitis and Crohn's disease in a regional patient group. Scand J Gastroenterol 1983; 18:987.

5. Rao SS, Holdsworth CD, Read NW. Symptoms and stool patterns in patients with ulcerative colitis. Gut 1988; 29:342. 
6. Sandle GI, Higgs N, Crowe P, Marsh MN, Venkatesan S, Peters TJ. Cellular basis for defective electrolyte transport in inflamed human colon. Gastroenterology 1990; 99:97.

7. Rao SS, Read NW, Brown C, Holdsworth CD. Studies on the mechanism of bowel disturbance in ulcerative colitis. Gastroentreology 1987; 93:934.

8. McEwen, JC, Ling C, Kirsner, JB. Arthritis accompanying ulcerative colitis. Am J Med 1962;33:923

9. Fernandez-Herlihy L. The articular manifestations of chronic ulcerative colitis: an analysis of 555 cases. N Engl J Med 1959;261:259.

10. Miller MM. Ankylosing spondylitis, Reiter's syndrome, psoriatic arthritis and arthritis of inflammatory bowel disease. Prim Care $1984 ; 11: 271$

11. Baioco PJ, Gorman BD, Korelitz BJ. Uveitis occurring after colectomy and ileal rectal sleeve anastomosis for ulcerative colitis. Dig Dis Sci 1984;29:570.

12. Toader E, Rusu L, Croitoru L, Arhip O, Mihaila C. Epidemiology of ulcerative colitis in north- eastern Romanian areas. J Preven Med 2006; 14: 71-78.

13. Khan HA, Mahrous AS, Fachartz, Khawaja FI. Ulcerative colitis amongst the Saudis: Six-year experience from Al-Madinah region. Saudi J Gastroenterol 1996;2:69-73.

14. Skrzydło-Radomańska B, Radwan $\mathrm{P}$, Radwan-Kwiatek $\mathrm{K}$. Retrospective analysis of hospital admission of patients with ulcerative colitis and crohn's disease from semi-rural and rural regions in the department of gastroenterology in Lublin between 2000-2006. Ann Agric Environ Med 2008; 15: 193-197.

15. Morita N, Toki S, Hirohashi T, Minoda T, Ogawa K, Kono S, et al. Incidence and prevalence of inflammatory bowel disease in Japan: nationwide epidemiological sur-vey during the year 1991. J Gastroenterol 1995; 30:1-4.
16. Qureshi H, Zuberi SJ, Banatwala N, Anwar A, Shamsi Z, Khan MN. Ulcerative colitis in Karachi. J Gastroenterol Hepatol 1989; 4:313-316.

17. Sood A, Midha V, Sood N, Puri S, Kaushal V. Profile of Ulcerative Colitis in a North Indian Hospital. J Ind Acad Clin Med 2000; 5:124-128.

18. Saro Gismera C, Lacort Fernández M, Argüelles Fernández G, Antón Magarzo J, Navascues CA, Garcia López R, et al. Epidemiology of chronic inflammatory bowel disease in Gijón, Asturias. Gastroenterol Hepatol 2001; 24:228-235.

19. Qian C, Jian-min SI, Min G, Gang Z, Wei-ling HU, Jin-hong LI. Clinical presentation of inflammatory bowel disease: a hospital based retrospective study of 379 patients in eastern China. Chinese Medical Journal 2005; 118 : 747-752.

20. Tan YM, Goh KL. Ulcerative colitis in a multiracial Asian country: Racial differences and clinical presentation among Malaysian patients, World J Gastroenterol 2005;11:5859-5862.

21. Feir S. Demographic profile and clinical presentation of Inflammatory bowel disease in the Philippine general hospital from 1999-2004. Phil J of Gastroenterology 2006; 2:95-102.

22. Pongprasobchai S, Manatsathit S, Leelakusolvong S, Sattawatthamrong Y, Boonyapisit S. Ulcerative colitis in Thailand: a clinical study and long term follow-up. J Med Assoc Thai 2001;84:1281-8.

23. Rajput HI, Seebaran AR, Desai Y. Ulcerative colitis in the Indian population of Durban. S Afr Med J 1992;81:245 8.

24. Mir-Madjlessi SH, Forouzandeh B, Ghadimi R. Ulcerative colitis in Iran: a review of 112 cases. Am J Gastroenterol 1985; $80: 862-866$.

25. Kochhar R, Mehta SK, Nagi B, Bhatia V, Goenka MK, Malik AK. Extraintestinal manifestations of idiopathic ulcerative colitis. Indian J Gastroenterol 1991;10:88-89. 